\title{
Experimental Study of Single Bed Silica Gel-water Adsorption Chiller
}

\author{
L.A. Dahake ${ }^{1, *}$, S.P. Komble ${ }^{1}$, K.A. Goudiya ${ }^{2}$ \\ ${ }^{1}$ Department of Mechanical Engineering, Vishwakarma Institute of Technology, India \\ ${ }^{2}$ Department of Mechanical Engineering, Dr. Babasaheb Ambedkar College of Engineering \& Research, India
}

Copyright $@ 2015$ Horizon Research Publishing All rights reserved.

\begin{abstract}
Adsorption refrigeration system are of significance to meet the need for cooling requirements such as ice making, food preservation and also it can works on solar energy or waste heat. Adsorption refrigeration system has various advantages over traditional refrigeration system. This covers the performance of commonly used adsorption pair. A model is constructed for the experimental investigation of single bed silica gel/water adsorption chiller. This paper includes the working principles of the adsorption system and includes sorption refrigeration cycle, it also mentioned the properties of the adsorption pairs.
\end{abstract}

Keywords Adsorption, Refrigeration

\section{Introduction}

Refrigeration is a process in which work is done to move heat from one location to another. The work of heat transport is traditionally driven by mechanical work with use of electricity. Refrigeration has many applications, including, but not limited to household refrigerators, industrial freezers, cryogenics and air-conditioning.

Economizing energy, environmental protection and sustainable development are all the main themes of the contemporary world in the $21^{\text {st }}$ century. In order to protect the ozonosphere in the atmosphere and the ecological environment, the treaty system of ozone layer protection made. But the deterioration still continues. According to the newly observation of NASA, the holes in the ozonosphere over the North and South Poles has surprisingly enlarged to about $28,300,000 \mathrm{~km}^{2}$ since this holes with $24,000,000 \mathrm{~km}^{2}$ was firstly observed in 1994. This unprecedented growth speed of the holes in the ozonosphere indicates that depleting of ozone has not been effectively controlled. The utilization of CFCs will be restricted more severely. Therefore, many attempts have been made to replace the traditional CFCs vapour compression refrigeration. However, the adsorption refrigeration machine can use natural working fluids as the refrigerants.
There is a large demand for cooling of food and vaccines in the developing countries. Vapour compression refrigerator requires electricity supply, which is often only available in urban areas. Indian scenario, as per Dec 2011, over 300 million Indian citizens had no access to electricity. Over one third of Indian's rural population lacked electricity, as did $6 \%$ of the urban population. Of those who did have access to electricity in India, the supply was intermittent and unreliable. In 2010, blackouts and power shedding interrupted irrigation and manufacturing across the country. So the adsorption refrigeration is an environment friendly, cost effective, reliable, and simple in design \& convenient refrigeration method because of its zero ODP (Ozone Depleting Potential).

\section{Literature Review}

D.S.Kim, C.A. Infante Ferreira, (2008) presents the different technologies that are available to deliver refrigeration from solar energy. K. Sumathy, K.H. Yeung, Li Yong. (2003) covers the principle of adsorption, various mathematical model and properties of refrigerents and adsorbents. L.W. Wang, R.Z. Wang, R.G. Oliveira, (2006) presents effective use of waste heat and solar energy as power source, It also includes the various design and performance parameters. C.J Chen, R.Z. Wang, Z.Z Xia, J.K. Kiplagat, (2010), used various mathematical models, it shows the use of $\mathrm{CaCl}_{2}$

\section{Research Methodology}

\subsection{Principle of Adsorption}

Adsorption occurs at the surface interface of two phases, in which cohesive forces including electrostatic forces and hydrogen bonding, act between the molecules of all substances irrespective of their state of aggregation. Unbalanced surface forces at the phase boundary cause changes in the concentration of molecules at the solid/fluid interface. The process of adsorption involves separation of a 
substance from one phase accompanied by its accumulation or concentration at the surface of another. The adsorbing phase is the adsorbent, and the material concentrated or adsorbed at the surface of that phase is the adsorbate.

To understand the adsorptive solvent recovery, some fundament of adsorption and desorption must be considered, as shown in Figure 1.

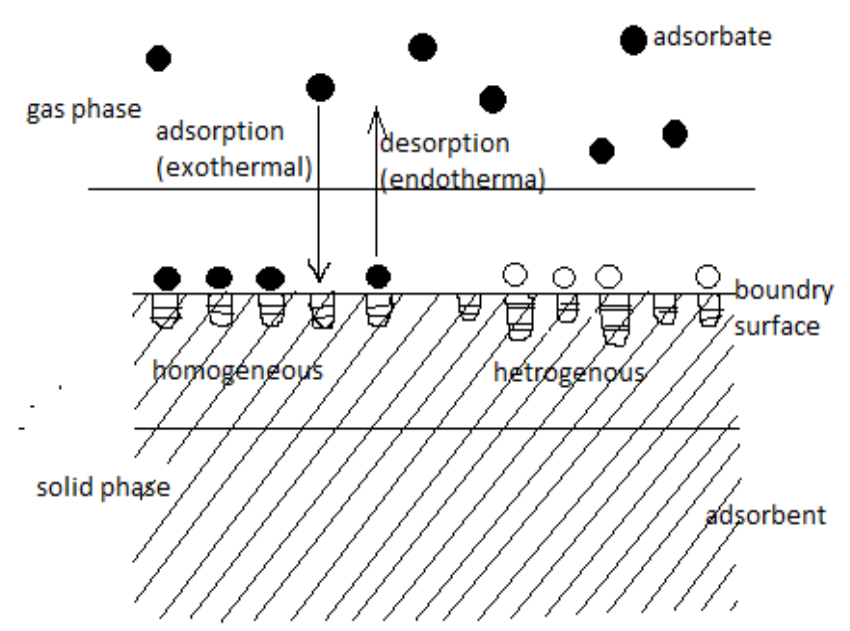

Figure 1. Fundamental of Adsorption and Desorption Processes

\subsection{Sorption Refrigeration Cycle}

The sorption refrigeration cycle is a thermodynamic cycle with two sources and two sink, which operates using three temperature levels. Two of them are used to drive the thermal "Reactor" that replaces the mechanical compressor in a vapour compression refrigeration cycle which shows in Figure 2. The sorption refrigeration cycle operates between two pressures and two refrigerant / sorbent concentration levels as shown in Figure 3.

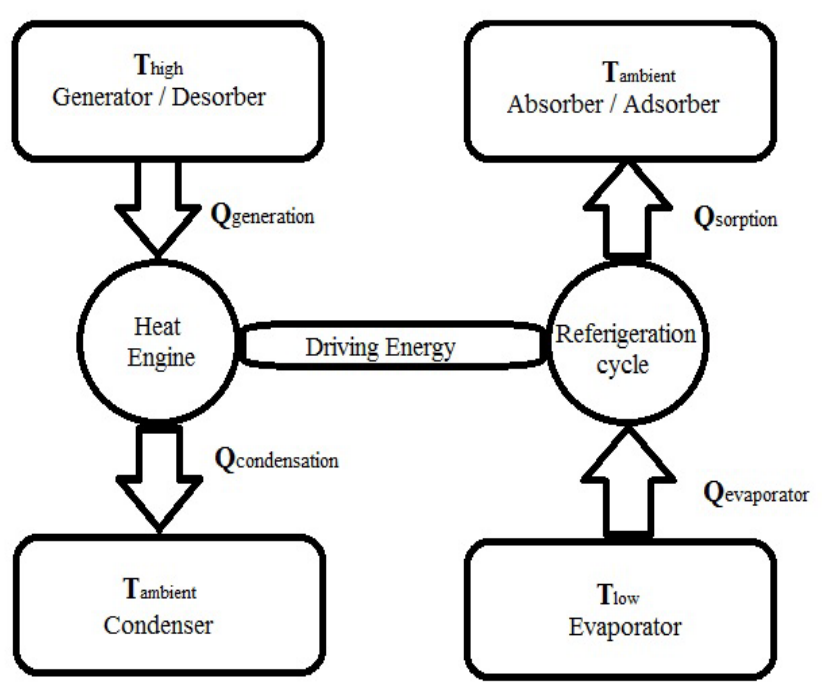

Figure 2. sorption thermodynamic cycle

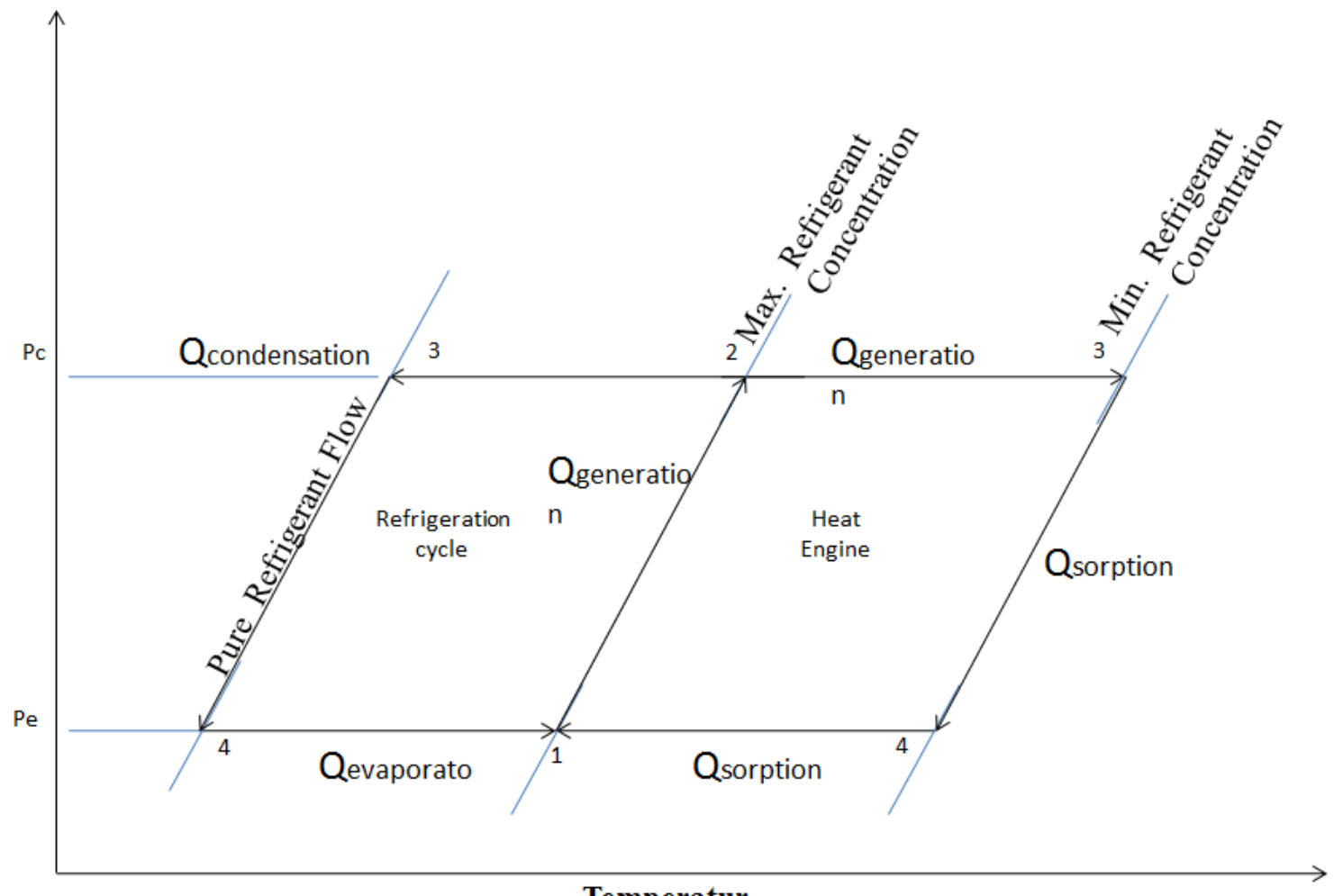

Temperatur

Figure 3. sorption clapeyron diagram 


\subsection{Experimental Set-up}

This is schematic diagram of actual experimental test rig with various components and calibrated instruments.

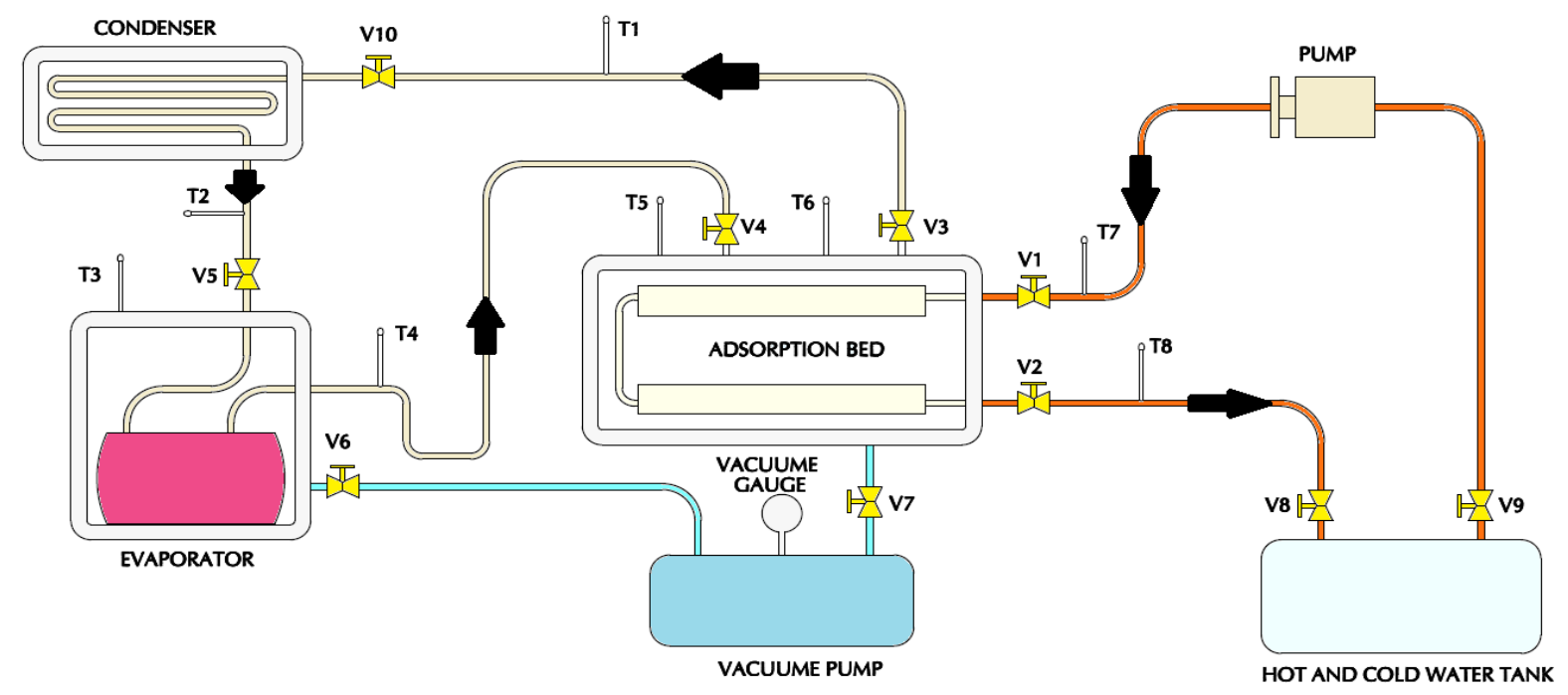

Figure 4. Set-up of Single Bed Silica Gel-Water Adsortion Chiller

Table 1. Characteristics of commonly used Adsorption Pairs

\begin{tabular}{|c|c|c|c|c|c|c|}
\hline & $\begin{array}{c}\text { AC, ACF, } \\
\text { AMMONIA }\end{array}$ & $\begin{array}{c}\text { AC, ACF, } \\
\text { METHANOL }\end{array}$ & $\begin{array}{c}\text { AC, ACF, } \\
\text { ETHANOL }\end{array}$ & $\begin{array}{c}\text { AC, ACF, } \\
\text { R134a }\end{array}$ & $\begin{array}{c}\text { SILICA GEL } \\
\text { / WATER }\end{array}$ & $\begin{array}{c}\text { ZEOLITE / } \\
\text { WATER }\end{array}$ \\
\hline Operating Pressure & Positive & Vacuum & Vacuum & Positive & Vacuum & Vacuum \\
\hline Generating Temperature ${ }^{0} \mathrm{C}$ & $80-200$ & $80-100$ & $80-120$ & $80-100$ & $50-100$ & $250-300$ \\
\hline $\begin{array}{c}\text { Adsorption } \\
\text { Capacity } \mathrm{Kg}_{\text {ref }} / \mathrm{Kg}_{\text {ads }}\end{array}$ & 0.29 & 0.45 & 0.19 & 0.36 & 0.30 & 0.17 \\
\hline Refrigerant Boiling Point ${ }^{0} \mathrm{C}$ & -34 & 65 & 79 & -48 & 100 & 100 \\
\hline $\begin{array}{c}\text { Refrigerant Latent heat of } \\
\text { Vaporisation } \mathrm{kJ} / \mathrm{Kg}\end{array}$ & 1368 & 1102 & 842 & 217 & 2258 & 2258 \\
\hline
\end{tabular}

\subsection{Adsorption Pairs}

Evaluation of adsorbent or adsorbate (refrigerant) independently is not sufficient, where adsorption characteristics vary based on adsorption pairs. Table 1 presents the characteristics of the most commonly used adsorption pair based on the practical operating conditions. The best adsorption pairs are the one that satisfies the important requirements which differs depending on the application.

\section{Results}

Based on experimental test rig performance, the experimental data is obtained under different operating processes of the chiller. The experimental results is obtained at the hot water inlet temperature $88^{\circ} \mathrm{C}$ and the cooling water temperature $32^{\circ} \mathrm{C}$, The predicted cooling temperature difference is 2.5 to $3^{\circ} \mathrm{C}$ and with $\mathrm{COP}$ is 0.27 which is considerable. The COP is obtained by using following mathematical relations.

$$
Q_{\text {evap }}=\frac{\int_{0}^{\mathrm{t}_{\text {cycle }}} \mathrm{m}_{\text {chw }} \mathrm{C}_{\mathrm{w}}\left(\mathrm{T}_{\text {chw,in }}-\mathrm{T}_{\text {chw,out }}\right) \mathrm{dt}}{\mathrm{t}_{\text {cycle }}}
$$

$$
\begin{gathered}
Q_{\text {heat }}=\frac{\int_{0}^{t_{\text {cycle }}} \mathrm{m}_{\text {hw }} C_{w}\left(T_{\text {hw,in }}-T_{\text {hw,out }}\right) d t}{t_{\text {cycle }}} \\
\operatorname{COP}=\frac{Q_{\text {evap }}}{Q_{\text {heat }}}
\end{gathered}
$$

\section{Discussion}

We have demonstrated the theoretical and experimental way of understanding of adsorption cooling system. This paper studied theoretically and experimentally the performance of silica gel / water adsorption cooling systems. An experimental test has been constructed to be used as performance evaluation tools. This paper presents an overall review on the basic fundamental understanding on the adsorption refrigeration cycles and also performance(COP) of the test rig. These results can perform the important role for the further improvements in this sector.

\section{Conclusions}

Adsorption cooling system have received significant 
interest during the last few decades in order to satisfy the market demand of cooling systems and cope with the current environmental issues. In this paper three main objective of the project is mentioned, 1) Importance of the adsorption system 2) Theoretical study of the adsorption refrigeration system. 3) Experimental investigation of the test rig. However the main disadvantages as long, adsorption and desorption time have become obstacles for industrial as well as commercial used of the adsorption system. Hence to compete with the traditional absorption and vapour compression refrigeration systems more efforts should be made in enhancing the COP by using different pairs. If there will be significant development in adsorption system then it will be the future of cooling industries and also it can widen the area of application of adsorption technologies and make the adsorption refrigeration more cost effective.

\section{REFERENCES}

[1] Kim D.S, Infante Ferreira C.A., (2008), "solar refrigeration options -a state of art review", International journal of refrigeration, 31(14) 3-15.

[2] Sumathy K.,Yeung K.H.,Yong Li. (2003),“Technology development in the solar adsorption refrigeration systems". Progress in Energy and Combustion Science, 29(27) 301-327.

[3] Wang L.W, Wang R.Z., Oliveira R.G. (2009), “A review on adsorption working pairs for refrigeration"., Renewable and Sustainable Energy Review,13(16) 518-534.

[4] Wang L.W., Wang R.Z., Oliveira R.G., (2006), "An efficient way to make good use of waste heat and solar energy", Progress in Energy and Combustion Science,32 (35) 424-458

[5] Chen C.J, Wang R.Z., Xia Z.Z, Kiplagat J.K., (2010), "Study on silica gel- water adsorption chiller integrated with a closed wet cooling tower" ,International journal of Thermal Science, 49(10)611-620. 